\title{
Judiciário: mudanças e reformas
}

\author{
Maria Tereza Sadek
}

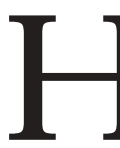

A TANTO TEM PO se ouve falar em crise e em reforma do Judiciário que os mais céticos não teriam dificuldades em encontrar argumentos a favor do imobilismo. O sidealistas, por seu lado, continuam propugnando por uma justiça só realizável em tempo e locais indefinidos. E os realistas? Teriam eles al guma base para contradizer céticos e ideal istas, sustentando que nem tudo está perdido e que cintilam luzes mesmo antes do final do túnel?

0 argumento central deste artigo é o de que o Judiciário brasileiro, diferentemente do que ocorria no passado, está na berlinda e não apresenta mais condições de impedir mudanças. Reformas virão e mudanças já estão em curso, algumas mais e outras menos visíveis, alterando a identidade e o perfil de uma instituição que sempre teve na tradição uma garantia segura contra as inovações.

Para a exposição deste argumento, em primeiro lugar, será discutida a peculiaridade do J udiciário brasileiro; em seguida, os principais temas em debate nas propostas de reforma; e, por fim, serão salientadas as mudanças em andamento e as perspectivas de reformas.

\section{Judiciário: poder de E stado e órgão prestador de serviços}

O Judiciário brasileiro tem duas faces: uma, de poder de Estado e, outra, de instituição prestadora de serviços. 0 modelo de presidencialismo consagrado pela Constituição de 1988 conferiu ao J udiciário e aos seus integrantes capacidade de agirem politicamente, quer questionando, quer paralisando políticas e atos administrativos, aprovados pelos poderes Executivo e Legislativo, ou mesmo determinando medidas, independentemente da vontade expressa do Executivo e da maioria parlamentar. Por outro lado, a instituição possui atribuições de um serviço público encarregado da prestação jurisdicional, arbitrando conflitos, garantindo direitos.

A face política do Judiciário foi claramente expressa pela Constituição de 1988. A Lei Maior brasileira, tal como as Constituições que resultaram dos processos de redemocratização no século XX, é muito diferente das precedentes, típicas do constitucionalismo moderno. Enquanto nas primeiras Constituições os principais objetivos eram a limitação do poder dos monarcas, a afirmação do império da L ei e a proteção das liberdades individuais, as mais recentes guiam-se por valores democráticos, enfatizando os direitos sociais ${ }^{1}$. A meta não é apenas limitar o poder absoluto e assegurar direitos, mas ser um instrumento para a realização da justiça social e para a promoção de direitos, incorporando valores da igualdade social, econômica e cultural. Em conseqüência, o foco central passa a 
estar em questões concretas, de natureza social, política e econômica, fortalecendo a inclinação do D ireito de tornar-se pragmático, embaçando as fronteiras entre 0 D ireito e a política. D aí, também, a tendência das Constituições mais recentes serem extremamente detalhadas, procurando resolver temas vistos como relevantes e especificar metas, regras e políticas de governo.

A Constituição brasileira de 1988 levou ao extremo as potencialidades do constitucionalismo característico dos processos de redemocratização, incorporando ao máximo o paradigma normativo. Efetivamente, além de garantir os direitos individuais, típicos do liberalismo, consagrou uma ampla gama de direitos sociais e coletivos e definiu metas. Trata-se de texto essencialmente programático, com os direitos e deveres individuais e coletivos aparecendo antes mesmo da organização do E stado. A versão final, com seus 245 artigos, acrescidos de setenta em suas disposições transitórias, resultou de quase dois anos de trabalho, muitas negociações, árdua composição de idéias, interesses divergentes e costuras políticas. Somente um texto detalhista poderia sacramentar tantas demandas e garantir formalmente a reconstrução da sociedade e do Estado, tendo por metas o desenvolvimento e a igualdade social².

No desenho constitucional aprovado em 1988 algumas características devem ser salientadas:

- todos os princípios democráticos básicos que sustentam a fundação de um Estado governado pela L ei foram garantidos;

- direitos e garantias fundamentais foram ampliados de modo a incluir um amplo espectro de direitos supra-individuais, tais como direitos difusos e coletivos, e foram criados instrumentos necessários para a defesa desses direitos;

- a preocupação com a desigualdade social e econômica provocou a inclusão não só de preceitos de igualdade jurídica, mas de medidas afirmativas para diminuir ou solucionar esses problemas;

- foi ampliada a lista de artigos que não podem ser modificados, nem mesmo por emenda constitucional (cláusulas pétreas);

- houve ambigüidade em relação ao tipo de governo: por um lado, afirmação do sistema presidencialista e, por outro, criação de instrumentos típicos do sistema parlamentarista, como as medidas provisórias.

O tipo de sistema presidencialista escolhido adotou o princípio da separação e independência entre os poderes. Tal modelo, contudo, estimula mais o conflito entre os diferentes ramos do que a cooperação. I sto porque, ao mesmo tempo em que fortaleceu o L egislativo, ampliando sua capacidade de fiscalizar e controlar o Executivo, facultou ao Executivo a possibilidade de legislar por meio de medidas provisórias. Essas potencialidades aumentaram a responsabilidade do Judiciário de exercer a mediação política entre os dois outros poderes e no controle constitucional dos atos legislativos e de governo ${ }^{3}$. 
A extensão e a complexidade dos direitos sociais garantidos, bem como 0 grau de detalhamento combinados com a capacidade do J udiciário de exercer 0 controle da constitucionalidade das leis e atos normativos, propiciaram um aumento substancial das áreas de intervenção e atuação pública deste poder. A L ei M aior conferiu capacidade aos magistrados è̀s cortes judiciais de produzirem impactos sobre o processo de decisão política. Em decorrência, a Constituição transforma-se em um texto programático, operando-se um estreitamento da margem de manobra dos políticose, conseqüentemente, ampliando-se o papel político do Judiciário.

Ademais, os imperativos de natureza institucional decorrentes da Constituição de 1988 reforçam o papel e o protagonismo políticos do Judiciário e de seus integrantes. 0 modelo institucional adotado imprime uma face fortemente política ao J udiciário. E sta dimensão política do J udiciário possui estreita ligação com o presidencialismo.

0 ativismo judicial não é exclusivo de sistemas presidencialistas, podendo ocorrer também em parlamentares. No presidencialismo, no entanto, o J udiciário apresenta condições de desenvolver ao máximo esta potencial idade, uma vez que é definido como um poder independente e encarregado de exercer o controle da constitucionalidade das leis e dos atos dos demais poderes.

Por outro lado, o novo Constitucionalismo democrático impulsiona a tendência de crescente expansão do âmbito de intervenção do Poder Judiciário. Esse "novo" J udiciário, com papel ativo na vida coletiva, independe do sistema normativo, ci vil law ou common law. A experiência européia recente, em diversos países, com diferentes sistemas jurídicos, mostra, com clareza, a prevalência deste "novo Judiciário ativo", co-autor de políticas públicas.

No caso brasileiro, a Constituição de 1988, seguindo estas tendências, redefiniu profundamente o papel do J udiciário no que diz respeito à sua posição e à sua identidade na organização tripartite de poderes e, conseqüentemente, ampliou o seu papel político. Sua margem de atuação foi ainda alargada com a extensa constitucionalização de direitos e liberdades individuais e coletivos, em uma medida que não guarda proporção com textos legais anteriores. D essa forma, a C onstituição de 1988 pode ser vista como um ponto de inflexão, representando uma mudança substancial no perfil do Poder J udiciário, alçando-o para o centro da vida pública e conferindo-Ihe um papel de protagonista de primeira grandeza.

0 protagonismo do Judiciário, e também dos demais agentes do sistema de justiça, substantiva-se em um poder até então desfrutado apenas pelos representantes eleitos pelo povo, seja no Legislativo, seja no Executivo. Como afirma Vieira (1994, p. 76), "a democracia constitucional brasileira passou a ser mais constitucional que democrática" , ou seja, decisões majoritárias são limitadas em um alto grau pelo Judiciário ao exercitar sua atribuição de controle da constitucionalidade. Isto se reflete tanto no Supremo Tribunal Federal como nos demais tribunais sempre que estejam em jogo questões passíveis de serem 
examinadas à luz dos preceitos constitucionais - e estes, em uma Constituição detal hista, praticamente tudo abarcam.

Assim, ainda que a Constituição de 1988 não tenha alterado nem a estrutura nem a composição do STF, ao ampliar o rol de matérias que não podem ser objeto de deliberação do Executivo e do Legislativo, transferiu para os onze ministros da cúpula do J udiciário um enorme poder. D e forma semel hante, como resultado deste novo modelo, à tímida atuação da J ustiça Federal sucedeu uma extraordinária onda de intervenção dos juízes e TribunaisF ederais nas mais variadas áreas de política pública.

A estes aspectos deve-se somar também a estrutura monocrática do J udiciário brasileiro - uma hierarquia na qual as relações de mando e obediência são constrangidas pela garantia de independência de cada juiz. Este tipo de organização estimula a diversidade de decisões, quer entre juízes, quer entre tribunais.

Em síntese, o modelo institucional conferiu ao J udiciário um papel político relevante, legitimando a atuação pública da magistratura e transformando a arena judicial em um espaço que abriga e arbitra o confronto entre as forças políticas. A disputa política, em conseqüência, tem como palco, não apenas o Parlamento ou as relações entre o C ongresso e o Executivo, mas também varas e tribunais de justiça.

A Constituição de 1988 garantiu a independência e a autonomia do J udiciário. N o que se refere à estrutura, houve uma ampla reorganização e redefinição de atribuições nos vários organismos que o compõem. Para começar, o STF, como órgão de cúpula, passou a ter atribuições predominantemente constitucionais. Logo abaixo na hierarquia, foi criado o Superior Tribunal de J ustiça, que incorporou parte das atribuições antes concentradas no STF. Foram instituídos ainda o J uizado Especial de Pequenas C ausas e a J ustiça de Paz remunerada no âmbito das justiças dos Estados, dosTerritórios e do D istrito Federal. D esapareceu - Conselho Nacional da Magistratura, para dar lugar ao Conselho da Justiça Federal. 0 artigo 92 da Constituição assim nomeou os órgãos do Poder J udiciário: "I. O Supremo Tribunal Federal; II. O Superior Tribunal de Justiça; III. O s tribunais regionais federais e juízes federais; IV. O s tribunais e juízes do trabalho; V. O s tribunais e juízes eleitorais; VI. O s tribunais e juízes militares; VII. O s tribunais e juízes dos estados e do D istrito Federal e territórios".

O STF teve sua competência ampliada na área constitucional, tendo em vista a criação do mandado de injução e o considerável alargamento do número de agentes legitimados a propor ação de inconstitucionalidade (anteriormente atribuição exclusiva do procurador-geral da República) ${ }^{4}$. Cabe-lhe declarar a constitucionalidade ou não de leis e atos normativos em tese (ou seja, em ação direta contra a lei em si), atribuição jurídico-político própria de uma Corte Constitucional; julgar, em recurso extraordinário, as causas decididas em única ou última instância por outros tribunais, quando a decisão recorrida contrariar dispositivo da Constituição; declarar a inconstitucionalidade de tratado ou lei federal e/ ou 
julgar válida lei ou ato de governo local contestado em face da Constituição; julgar originariamente as causas em que a magistratura é direta ou indiretamente interessada. Foi-Ihe extraída, contudo, a função que desempenhara desde a sua criação, de tribunal unificador da aplicação do direito federal infraconstitucional e retirada a representação avocatória da sua lista de competências.

A grande inovação estrutural foi à criação do ST J, cujos principais fundamentos eram descongestionar o ST F e assumir al gumas das funções antes atribuídas ao Tribunal Federal de Recursos. É um órgão acima dos tribunais federais e dos tribunais dos Estados, com atribuições de guardar a legislação federal e de julgar em recurso especial as causas decididas em única e última instância pel os Tribunais Regionais Federais ou pelos tribunais dos Estados, dos Territórios e do D istrito Federal. Funcionando ao lado do STJ foi criado o Conselho da J ustiça Federal, com finalidade de supervisão administrativa e orçamentária da J ustiça Federal de primeira e segunda instâncias.

A J ustiça Federal, recriada em 1965, foi mantida, sendo extinto o Tribunal Federal de Recursos e instituídos tribunais regionais federais, com o objetivo de descentralizar a justiça de segundo grau.

Compõem ainda o Poder Judiciário as justiças especiais: a do trabalho, a eleitoral e a militar. C onferiu-se aos E stados a organização de sua justiça, cabendo às constituições estaduais a definição da competência dos tribunais, sendo a lei de organização judiciária de iniciativa do Tribunal deJ ustiça. A justiça dos Estados é formada por órgãos de primeiro e segundo grau.

Ao lado dessas modificações, também foram ampliados instrumentos jurídicos, responsáveis pela efetivação das obrigações constitucionais. D estacam-se, entre eles: o habeas corpus, o mandado de segurança, individual ou coletivo; 0 mandado dei njunção; o habeasdata; a ação popular; a declaração deinconstitucionalidade de lei ou ato normativo federal ou etadual; a inconstitucionalidade por omissão.

\section{Judiciário: crise e propostas de reforma}

Críticas ao desempenho das instituições encarregadas de distribuir justiça praticamente acompanharam a instalação e o desenvolvimento dessas organizações no país. Desde as primeiras Cortes, criadas ainda no período colonial, vozes se levantaram mostrando sua inoperância e o quanto distavam de um modelo de justiça minimamente satisfatório. Nos últimos tempos, entretanto, tornou-se dominante a idéia de que essas instituições, além de incapazes de responder à crescente demanda por justiça, tornaram-se anacrônicas e, pior ainda, refratárias a qual quer modificação. $\mathrm{N}$ as análises mais impressionistas sustenta-se, inclusive, que as instituições judiciais ficaram perdidas no século XVIII ou, na melhor das hipóteses, no XIX, enquanto o resto do país teria adentrado nos anos 2000.

A constância nas críticas à justiça estatal é um denominador absolutamente comum quando se examinam textos especializados, crônicas e mesmo debates 
parlamentares, ao longo dos últimos quatro séculos. Esse traço não é singular ao B rasil, ainda que, entre nós, possua características próprias. Recorrer à universalidade da crítica não significa pretender equiparar experiências, nem diminuir o tamanho do problema. Significa, isto sim, focalizar uma questão que é relevante e tem mobilizado o interesse de analistas e dirigentes políticos em todos os cantos do mundo.

A situação brasileira recente difere de todo o período anterior em pelo menos dois aspectos: 1) a justiça transformou-se em questão percebida como problemática por amplos setores da população, da classe política e do soperadores do Direito, passando a constar da agenda de reformas; 2) tem diminuído consideravelmente o grau de tolerância com a baixa eficiência do sistema judicial e, simultaneamente, aumentado a corrosão no prestígio do Judiciário.

É possível sustentar que a peculiaridade do caso brasileiro, como de resto da maior parte dos países latino-americanos, está na magnitude dos sintomas, indicando a necessidade de reformas. São inúmeras as pesquisas de opinião retratando a expressiva insatisfação da população com a justiça estatal. Levantamentos de institutos especializados mostram que, em média, 70\%dos entrevistados não confiam na justiça. Recentes investigações realizadas pelo I desp apontam que os indicadores mais gerais são igualmente válidos para setores de elite. Entre os empresários, por exemplo, o J udiciário é muito mal avaliado, chegando a 89\% os que o consideram "ruim" ou "péssimo", em termos de agilidade (I desp, 1996).

M esmo os operadores do sistema de justiça, tradicionalmente mais reservados em suas apreciações e vistos como portadores de forte espírito corporativo, têm reconhecido que as condições presentes são desfavorávei $5^{5}$. M agistrados, Promotores e Procuradores da República têm se mostrado sensíveis à existência de uma crise na justiça. Sublinhe-se, inclusive, que os operadores do Direito têm sido chamados a interferir no debate e suas associações representativas têm tido participação ativa quer propondo mudanças, quer impedindo que certas alterações sejam aprovadas.

A indiscutível insatisfação com a prestação jurisdicional, embora central na elaboração de qualquer diagnóstico, encobre questões diversas, provenientes de causas diferentes, provocando conseqüências distintas. Convém, pois, discernir as questões. Trata-se, certamente, de um problema que não se circunscreve à instituição, produzindo efeitos abrangentes, interferindo na ordem legal, passando pela garantia dos direitos individuais e coletivos e até mesmo interpondo sérios obstáculos à implementação de projetos de desenvolvimento e de inserção da economia nacional na nova ordem internacional.

\section{A dimensão política da crise do Judiciário}

A extrema visibilidade dos problemas decorrentes da dimensão política do Judiciário, nos últimos anos, decorre fundamentalmente do fato do país viver momentos de ajuste econômico, político e social e de adaptação de toda a sua 
infra-estrutura às exigências de inserção no mercado internacional, sob a égide de uma Constituição excessivamente detalhista. Essa visibilidade é tanto maior quanto mais amplo for o número de decisões majoritárias definidas pelo Congresso ou pelo Executivo que alterem o statusquo. Assim, em um país com uma ampla agenda de reformas e que adote um modelo institucional que alarga o espaço político do J udiciário, como éo caso do Brasil, os problemas oriundos da dimensão política são mais do que esperados, tornam-se inevitáveis.

A tendência à expansão da presença do Poder Judiciário na arena pública pode ser confirmada pelo expressivo aumento no número de ações diretas de inconstitucionalidade - 0 indicador clássico do processo de judicialização da política. De 1988 a janeiro de 2004 foram impetradas 3.097 ações. A participação de partidos políticos, de governadores de E stado e de confederações e entidades sindicais tem sido significativa, superando largamente o percentual de ações propostas pelo Procurador-G eral da R epública, o único agente, antes da vigência da Constituição de 1988, com legitimidade para propor esse tipo de ação.

A proposição de ações diretas de inconstitucionalidade não cobre 0 amplo potencial da dimensão política do Judiciário. A concessão de liminares, a possibilidade de decisões judiciais paralisan do medidas provenientes do Executivo e do Legislativo ou mesmo impondo determinadas resoluções preenchem essa dimensão, provocando reações por parte do governo, da classe política e de setores da sociedade. N esse sentido, são freqüentes as críticas segundo as quais vive-se em um "manicômio jurídico"; a magistratura age "ideológica e irresponsavelmente", como se os recursos públicos fossem inesgotáveis, ou alheia às conseqüências de suas decisões na economia ou na máquina administrativa; juízes julgam-se os "verdadeiros representantes do interesse do povo".

Saliente-se que a dimensão política do J udiciário provoca reações, sobretudo por parte do governo e dos partidos de sustentação do Executivo - independentemente do partido ou dos partidos que ocupem esta posição. $\mathrm{N}$ ão por acaso, 0 tema da reforma do sistema de justiça tem voltado ao debate obedecendo aos ciclos de decisões que alteram o status quo, quer por autoria do Executivo, do Legislativo ou do próprio Judiciário. D o ponto de vista do jogo político, podese mesmo afirmar que esta dimensão é apontada como a mais problemática e, portanto, sujeita a alterações radicais em um projeto de reforma.

\section{A dimensão não-política da crise do judiciário}

Esta dimensão contempla as funções do J udiciário relacionadas ao seu papel de organismo encarregado de distribuir justiça. D esse ângulo, cabe examinar a instituição como uma agência pública prestadora de serviços. Grande parte da insatisfação popular com a justiça refere-se a esta dimensão. A ela são dirigidas ácidas críticas, tais como: "a justiça tarda e falha"; "a justiça não é igual para todos"; " "a justiça é elitista" ; " mais vale um mal acordo do que uma boa demanda"; "para os amigos tudo para os inimigos a lei" etc. 
Para o exame dessa dimensão, uma vez mais, é necessário distinguir al guns aspectos. $\mathrm{H}$ á que se examinar, de um lado, a demanda por justiça e, de outro, $\mathrm{O}$ processamento desta demanda.

No que se refere à demanda, o crescimento nos índices de procura pela justiça estatal está altamente relacionado às taxas de industrialização e de urbanização. C rescimentos nesses indicadores provocam aumentos no número e no tipo de conflitos e, conseqüentemente, torna-se maior a probabilidade de que litígios convertam-se em demanda judicial. Essa potencialidade depende, por sua vez, da consciência de direitos e da credibilidade na máquina judicial. Assim, a mera transformação estrutural por que passou a sociedade brasileira, de predominantemente agrária e rural para industrial e urbana, num intervalo de menos de cinqüenta anos, tomando-se 1930 como ponto de partida, justificaria a multiplicação dos conflitos. Tais tendências foram, no entanto, em grande parte, contidas pela ausência de vida democrática e pelo descrédito na justiça6.

As dificuldades de acesso ao J udiciário são constantemente lembradas como um fator inibidor da realização plena da cidadania ${ }^{7}$. 0 desconhecimento dos direitos, por um lado, e a percepção de uma justiça vista como cara e lenta, de outro, afastam dos tribunais a maior parte da população. D aí afirmar-se que a grande massa só procura a justiça estatal quando não há outra al ternativa. N estas circunstâncias, não se trataria de uma utilização voluntária, para a efetivação de direitos, mas compulsória. I sto significa que a face do Judiciário conhecida por largos setores de jurisdicionados não é a civil, mas, sobretudo, a criminal ${ }^{8}$.

Esta constatação não se aplica, entretanto, a todos os estratos sociais. H á setores que buscam a justiça, extraindo vantagens de suas supostas ou reais deficiências, bem como dos constrangimentos de ordem legal. Este é o caso tanto de certos órgãos estatais como de grupos empresariais. Pesquisa conduzida pelo I desp junto a empresários, em 1996, revelava que, embora a principal crítica dirigida ao J udiciário fosse a falta de agilidade, esta deficiência nem sempre era avaliada como prejudicial para as empresas. Muitos empresários admitiram que a morosidade é por vezes benéfica, principalmente na área trabalhista9 ${ }^{9}$ Tal como as empresas, também o governo e agências públicas têm sido responsáveis pelo extraordinário aumento da demanda no J udiciário. Calcula-se que o Executivo e o INSS respondem por cerca de $80 \%$ das ações judiciais.

Resumidamente, pode-se sustentar que o sistema judicial brasileiro nos moldes atuais estimula um paradoxo: demandas de menos e demandas de mais. O u seja, de um lado, expressivos setores da população acham-se marginalizados dos serviços judiciais, utilizando-se, cada vez mais, da justiça paralela, governada pela lei do mais forte, certamente menos justa e com altíssima potencialidade de desfazer todo o tecido social. De outro, há os que usufruem em excesso da justiça oficial, gozando das vantagens de uma máquina lenta, atravancada e burocratizada. 
As deficiências do aparelho judicial, somadas aos ritos processuais, criam situações de vantagem e/ ou privilégios, portanto, de desigualdade. Assim, a ampla possibilidade de recursos facultada pela legislação favorece o "réu" , o "devedor", adiando uma decisão por anos. É consensual entre os especialistas a avaliação de que ingressar em juízo, no caso de quem deve, é um bom negócio, seja este réu o setor público ou particulares.

A pesar das críticas, todos os números referentes ao J udiciário são grandiosos. São milhares de processos entrados e milhares de julgados. De fato, quando se observa tanto a movimentação judicial anual quanto a evolução do número de processos entrados, não há como fugir de uma primeira constatação: a demanda por uma solução de natureza judicial tem sido extraordinária e crescente. Ainda que em magnitude relativamente menor, o mesmo pode ser dito sobre os processos julgados: um volume de trabalho apreciável.

Para que se tenha uma idéia, de 1990 a 2002, entraram, em média, na justiça comum de primeiro grau 6.350 .598 processos por ano, com clara tendência de crescimento. Efetivamente, enquanto em 1990 chegaram até o Judiciário 3.617.064 processos, em 2002 este número mais do que dobrou, atingindo 9.764.616. Durante esses anos houve, em média, um processo para cada 31 habitantes. Embora seja uma média e, como tal, esconda diversidades, revela um ângulo precioso dajustiça brasileira: um serviço público com extraordinária procura. 0 aumento no volume de processos entrados é muito maior do que faria supor 0 crescimento populacional. Enquanto o número de habitantes no período cresceu $20 \%$, a demanda pela justiça de primeiro grau aumentou $270 \%$

Q uanto aos processos julgados, sua evolução acompanhou o crescimento no número de entrados, apresentando uma média anual de 4.593.839. Entre 1990 e 2002 houve um aumento de $311 \%$ nos julgados. Contudo, os números referentes aos julgados, ano a ano, indicam uma defasagem constante quando comparados aos de entrados: são julgados em média $72 \%$ dos processos entrados.

Embora a justiça de primeiro grau concentre a maior parte dos processos, é também apreciável a movimentação dos tribunais. Comparando-se o início da década com o final, os resultados são sempre significativos. Entraram, em 1990, 125.388 processos nos Tribunais de J ustiça do país. Este número cresceu mais de quatro vezes em 2000, passando para 545.398. Q uanto aos processos julgados, registrava-se em 1990 um total de 114.237; em 2000, atingiu-se três vezes e meia mais: 410.304 julgamentos.

Tal como se passa na justiça dos Estados, é apreciável o movimento processual da justiça federal. 0 número de processos distribuídos no primeiro grau aumentou mais de cinco vezes de 1989 a 2002, assim como o de julgados. A defasagem entre distribuídos e julgados é sempre considerável: em média, são julgados $57 \%$ dos entrados. $N$ o que se refere aos tribunais regionais, enquanto em 1989 foram distribuídos 96.021 processos, em 2002, este número passou para 538.104 - um volume cinco vezes maior. Durante todo o período, é alta a 
diferença entre o número de processos entrados e julgados - tanto no país como em cada tribunal.

Repetem-se, em relação ao Superior T ribunal de J ustiça, as mesmas constatações: uma movimentação excepcional, com crescimentos vertiginosos nos volumes de processos distribuídos e julgados, e números multiplicando-se a cada ano. A mais alta corte de justiça do país apresenta totais que surpreenderiam a qualquer estudioso do sistema de justiça. Em 1940, chegavam até o STF 2.419 processos; em 1950, 3091; em 1960, 6.504; em 1970, 6.367; em 1980, 9.555; em 1990, 18.564; em 2000, 105.307; em 2001, 110.771; em 2002, 160.453. Trata-se, como se percebe, sobretudo a partir de 1980, de um crescimento extraordinário, demonstrando a intensa utilização desse tribunal. O s números de julgamentos são igualmente surpreendentes: 1.807 em 1940; 3.371 em 1950; 5.747 em 1960; 6.486 em 1970; 9.007 em 1980; 16.449 em 1990; 86.138 no ano de 2000; 109.692 em 2001; 283.097 em 2002.

\section{A estrutura para o processamento de demandas}

Este éo angulo que apresenta os sintomas mais visíveis do que se convencionou chamar de crise do Judiciário. Diz respeito a uma estrutura pesada, sem agilidade, incapaz de fornecer soluções em tempo razoável, previsíveis e a custos acessíveis para todos.

A despeito de se verificar tendências ascendentes na demanda e na oferta de serviços em todas as instâncias e em todas as justiças, a imagem é de absoluta inoperância, com descompasso expressivo entre a procura ea prestação jurisdicional. Calcula-se que, caso cessassem de ingressar novos casos, seriam necessários de cinco a oito anos, dependendo do ramo do Judiciário e da unidade da federação, para que fossem colocados em dia todos os processos existentes. Como explicar esta situação crítica?

Com freqüência, aponta-se o número insuficiente de juízes como um dos fatores mais importantes para justificar a baixa agilidade no desempenho do Judiciário ${ }^{10}$. M uitos integrantes do sistema de justiça apegam-se a esta carência para explicar a crise. D e fato, o B rasil apresenta uma rel ação bastante desfavorável entre o número de magistrados e o tamanho de sua po pulação. A demais, o baixo número de juízes é um problema reconhecido pelo próprio poder público, já que, em todas as unidades da Federação, há vagas abertas. Apesar da inegável desvantagem da situação brasileira quando confrontada com a de outros países, estudos comparativos internacionais demonstram não haver correlação significativa entre 0 número de juízes e a eficiência e a confiança da população no sistema judicial (Buscaglia et al., 1995).

Embora seja difícil apontar uma única causa como responsável pelos problemas de distribuição de justiça, seria impossível ignorar o papel desempenhado pelos próprios magistrados no exercício de suas atribuições. Referimonos a dois aspectos: ao recrutamento e à mentalidade, variáveis com forte influência 
na forma de perceber e de lidar com as questões relacionadas à distribuição de justiça.

O recrutamento, no caso brasileiro, é uma atribuição da própria instituição. 0 ingresso na carreira depende de concurso público, para o qual estariam teoricamente habilitados os bacharéis em $D$ ireito. A proliferação de faculdades, sobretudo a partir dos anos de 1970, não foi acompanhada de igual preocupação com a qualidade dos cursos. Este fenômeno explicaria, em boa medida, o reduzido índice de aprovados nos concursos de ingresso e, conseqüentemente, a vacância em todas as regiões do país. M as certamente está aí apenas parte da explicação. $\mathrm{H}$ averia que se considerar também fatores estranhos a uma prova de proficiência, como, por exemplo, uma política deliberada para impedir o crescimento exagerado no número de integrantes da instituição e seus efeitos deletérios sobre o prestígio e as deferências típicos de um grupo pequeno e mais homogêneo. Esta hipótese ganha força quando se considera que o sistema de recrutamento adotado no país permite 0 acesso de profissionais extremamente joven ${ }^{11}$, sem a obrigação de passagem por escolas de formação, isto é, sem a sujeição a um processo formal de socialização interna corporis

Q uanto à mentalidade, o Judiciário não difere, neste aspecto, de outras instituições igualmente fechadas, com traços aristocráticos. 0 figurino da instituição tem se mostrado um ponto problemático, uma vez que, longe de encorajar o substantivo, prende-se à forma; em vez de premiar o compromisso com o real, incentiva o saber abstrato. 0 descompasso entre 0 valorizado pela instituição e as mudanças vividas pela sociedade responde, em grande parte, pela imagem negativa da magistratura junto à população. Sublinhe-se, contudo, que nos últimos anos têm crescido as reações internas a esse modelo. Tanto assim que, hoje, dificilmente, pode-se afirmar que a magistratura constitua um corpo homogêneo. Ao contrário, não apenas multiplicaram-se os grupos internos, como muitos juízes têm se mostrado críticos da instituição e sensíveis a propostas de mudança, mesmo que afetem diretamente interesses corporativos e tradicionais. Ainda que esses grupos não sejam majoritários, constata-se uma significativa renovação interna, no sentido de um maior pluralismo ${ }^{12}$ e a uma conseqüente quebra no modelo de mentalidade tradicional. Esta mudança não deve ser vista como apenas positiva. Ela embute riscos, sobretudo se implicar uma ampliação do espaço de partidários de um "direito alternativo", comprometidos com uma concepção de justiça social, que tem no magistrado um paladino ${ }^{13}$, ou ainda de juízes que, ao abandonar a discrição, guiem-se pela presença na mídia e pela ânsia de substituir a classe política, constituída pelo mandato popular.

O utros fatores poderiam concorrer para a explicação da falta de agilidade da estrutura burocrática do J udiciário. D entre eles, saliente-se: escassez de recursos materiais e/ ou deficiências na infra-estrutura; o conjunto de problemas relacionado à esfera legislativa propriamente dita e aos ritos processuais. 
M esmo reconhecendo a importância dos recursos materiais, estudos comparativos internacionais demonstram que incrementos em recursos não provocam iguais ganhos em agilidade e previsibilidade dos serviços prestados.

Q uanto aos problemas relacionados à esfera legislativa, considera-se que a morosidade da justiça também tem a ver com as normas processuais, isto é, com os efeitos e dificuldades que podem decorrer das próprias etapas e garantias especificadas em lei. A discussão dessas normas tem como horizonte a possível simplificação do processo, com a implantação de procedimentos mais rápidos, simples e econômicos.

Além da instabilidade legal que tem marcado o país, o excesso de formalidades também contribui para retardar o trabalho da justiça. D epoimentos de vários membros do J udiciário e de estudiosos apontam na direção da necessidade de uma reformulação na lei processual vigente, buscando simplificá-la, removendo diversos óbices legais que impedem a agilidade dos diversos juízes, nos vários graus de jurisdição. Investigações comparativas concluem que esses problemas mostram-se centrais como entrave à agilidade do Judiciário. No caso brasileiro, os dados disponíveis sugerem que o número de recursos possíveis, mais do que contribuir para a garantia de defesa de direitos, tem propiciado a litigância de má fé, o adiamento de decisões. $D$ aí os congestionamentos na justiça de segundo grau e o retardamento, por anos, na obtenção de sentenças definitivas.

\section{Propostas de reforma}

O capítulo referente ao sistema de justiça da Constituição de 1988 foi 0 que recebeu 0 maior número de propostas de revisão, por ocasião da reforma constitucional de $1993^{14}$ - foram ao todo 3.917 emendas. U m número nada desprezível, mas de todo incongruente com o resultado então alcançado: nenhuma alteração.

Como conseqüência, a proposta de emenda constitucional relativa ao Judiciário tramita no Congresso $\mathrm{N}$ acional há mais de uma década, a partir de um projeto apresentado por H élio Bicudo em 1992, então deputado federal pelo PT de São Paulo. Esse primeiro projeto sofreu inúmeras modificações, atéfinalmente ser votado na Câmara dos D eputados, em junho de 2000. Tantas foram às alterações e de tal magnitude que é possível afirmar que entre o primeiro projeto e o aprovado praticamente não há semel hanças. $M$ ais do que isso: após o período de revisão constitucional, sucederam-se três relatores ${ }^{15}$ e apesar de todos pertencerem a partidos governistas, resultaram três propostas absolutamente diferentes entre si. E m junho de 2004, o texto encontrava-se no Senado, na Comissão de Constituição, Justiça e Cidadania, aguardando parecer do relator, podendo, inclusive, ser inteiramente modificado.

As soluções propostas, para efeito de discussão, poderiam ser agrupadas em dois grupos: as judiciais propriamente ditas e as extrajudiciais, aí englobando desde sistemas alternativos para a solução de disputas até modificações legislativas. 
As propostas de reforma denominadas judiciais procuram dar maior eficiência ao Poder Judiciário a partir de intervenções internas, na própria instituição. Abrangem, assim, iniciativas diversas, desde alterações nas competências de seus organismos até modificações na estrutura da instituição. Entre elas destacam-se: transformação do STF em uma Corte de Justiça; introdução da súmula de efeito vinculante; da súmula impeditiva de recurso; do incidente de constitucionalidade; eliminação de juízes classistas naJ ustiça do Trabalho; extinção da J ustiça M ilitar; fim do poder normativo da J ustiça do Trabal ho; criação de um órgão de controle externo do Poder Judiciário.

$\mathrm{N}$ o que se refere ao perfil institucional do J udiciário, a proposta com maior potencialidade de alterar as relações entre este poder e os poderes propriamente políticos diz respeito à transformação do STF em uma Corte Constitucional. E sta modificação teria por finalidade dois objetivos: restringir a atuação do órgão a questões estritamente constitucionais, deixando de ser um Tribunal de última instância para qualquer tipo de demanda e redefinir o exercício do controle da constitucionalidade. Com o primeiro objetivo, seria reduzido significativamente o número de processos que chega até a mais alta corte de justiça. $\mathrm{No}$ atual modelo, toda e qualquer matéria pode, através de recursos, chegar até o STF, obrigando seus ministros a lidar com um rol tão amplo de questões que não encontra paralelo nas demais democracias. A redefinição do controle da constitucionalidade, por sua vez, alteraria profundamente toda a engenharia institucional. O s partidários mais radicais desta alteração inspiram-se em um modelo no qual o controle da constitucionalidade das decisões políticas deve limitar-se a princípios que ponham em risco a continuidade democrática e o Estado de Direito. N essa alternativa não caberia ao J udiciário pronunciar-se sobre toda e qual quer questão, passando a adquirir as decisões majoritárias (aprovadas no Congresso ou propostas pelo Executivo) prevalência sobre as judiciais. Seria, pois, reduzida a possibilidade de ativismo do Judiciário e, ao mesmo tempo, seriam flexibilizados os preceitos constitucionais e reduzido o número de cláusulas pétreas.

Em uma outra versão, seria reforçado o papel do ST F e dos Tribunais superiores, facultando a essas cortes a emissão de Súmulas e a elas atribuindo efeito vinculante para os demais órgãos do Judiciário e para a Administração D ireta e Indireta de todas as esferas do poder público. Alcançar-se-ia, assim, a uniformização dosjulgados e condicionar-se-iam as ações administrativas do poder público. A decisão de um tribunal superior teria que ser obrigatoriamente seguida no julgamento de um caso semelhante. Essas súmulas teriam força de lei.

A súmula de efeito vinculante (staredecisis) é vista por seus defensores como indispensável para garantir a segurança jurídica e evitar a multiplicação, considerada desnecessária, de processos nas várias instâncias. Tal providência seria capaz de obrigar os juízes de primeira instância a cumprir as decisões dos tribunais superiores, mesmo que discordassem delas, e impediria que grande parte dos processos tivesse continuidade, desafogando o J udiciário de processos repetitivos. 
Seus oponentes, por seu lado, julgam que a adoção da súmula vinculante engessaria o Judiciário, impedindo a inovação e transformando os julgamentos de primeiro grau em meras cópias de decisões já tomadas. D entre os que contestam tal expediente, há os que aceitam a súmula impeditiva de recurso, um sistema em que o juiz não fica obrigado a seguir o entendimento dos tribunais superiores e do ST F, mas permite que a instância superior não examine o recurso que contrarie a sua posição.

O utra modificação de grande amplitude seria a criação de incidente de inconstitucionalidade, que permitiria ao ST F, provocado pelo Procurador-Geral da República, Advogado da U nião, Procurador-Geral ou Advogado-Geral do Estado, determinar a suspensão de processo em curso perante qualquer juízo ou tribunal, para proferir decisão exclusivamente sobre a questão constitucional suscitada, obrigando os demais órgãos do Judiciário a adotar a mesma interpretação no julgamento de casos concretos.

Essas propostas encontram resistências por parte da magistratura, sobretudo de primeira instância, de setores do M inistério Público e de amplo grupo de juristas, particularmente da O AB. Tais inovações, na opinião de seus oponentes, afrontariam duas garantias constitucionais: a) a separação de poderes, uma vez que daria poder normativo aos tribunais - uma prerrogativa do Legislativo; b) 0 princípio do duplo grau de jurisdição, já que retiraria dos magistrados o poder de decidir livremente, segundo a lei e o seu convencimento pessoal. Alega-se ainda que essas soluções visam a fortalecer o órgão de cúpula do Judiciário e propiciar agilidade aos tribunais, implantando uma ditadura e impedindo a autonomia do juiz e, conseqüentemente, a oxigenação da instituição.

No que se refere ao conjunto de problemas denominados estruturais, também é amplo o leque de propostas, abrangendo desde alterações na estrutura do poder Judiciário até modificações nas competências de certos órgãos. Assim, há projetos com o objetivo transformar o STF em Tribunal Constitucional, no estilo dos modelos europeus, composto por juízes com mandato fixo. Essa transformação faria com que o STJ fosse ampliado, cabendo a ele a uniformização da jurisprudência relativa à legislação federal e à proteção das liberdades fundamentais. Trata-se de proposta polêmica, encontrando ferrenhos adversários no interior da magistratura e entre juristas.

Q uanto às justiças especiais, a solução que sempre obteve um maior número de adeptos era a que determinava a extinção do cargo de juiz classista na J ustiça do Trabalho. Tal demanda, de fato, acabou sendo efetivada, por meio de Emenda Constitucional, em dezembro de 1999, deixando, pois, de constar da proposta de Reforma do Judiciário. H á ainda emendas visando a alterar os artigos 111, 112, 113 e 114 da Constituição Federal para extinguir o TST, a representação classista em todos os graus de jurisdição e o poder normativo da J ustiça do Trabalho. Essa inovação, que mudaria efetivamente o perfil institucional da Justiça do Trabalho, visa a possibilitar a implantação definitiva da negociação coletiva 
em matéria trabal hista. Argumentam seus defensores que, desta forma, o país daria um salto de qualidade nas relações de trabalho, assemelhando-se ao que o corre nos países capitalistas avançados. Ali, a legislação limita-se a normas gerais, assim como é restrita a intervenção de terceiros nas relações trabalhistas.

No que se refere à Justiça M ilitar, há propostas pretendendo reduzir a competência de seus juízes, redefinindo os tipos de crimes sujeitos a seu julgamento, quando cometidos por militares ou policiais militares. Há também propostas objetivando incluir a J ustiça Agrária entre os órgãos do Judiciário.

A democratização do Poder J udiciário, no sentido de abertura de suas portas para os setores mais carentes da população, inspira propostas que prevêem a criação de novos J uizados Especiais, especialmente na justiça trabalhista. Esses juizados foram implantados na justiça federal e começaram a operar em janeiro de 2002.

A criação de um órgão externo de controle do J udiciário é, sem dúvida, a proposta que mais tem provocado discussões. Desde que foi apresentada encontrou ardorosos defensores e recebeu uma avalanche de protestos. Seus adeptos sustentam que, dos três poderes, o Judiciário é o mais estável e o que tem menos mecanismos de controle e de fiscalização, seja por parte da sociedade, seja de outros poderes. Essa proposta já sofreu uma série de modificações, tanto no que se refere à denominação do órgão encarregado de exercer controle, como quanto às suas competências e à participação de membros externos à instituição.

As soluções extrajudiciais contemplam iniciativas que vão da esfera legislativa propriamente dita até a criação de novos espaços para a solução de disputas. Problemas decorrentes da legislação têm sido repetidas vezes apontados como sérios obstáculos ao bom funcionamento da justiça. Parece existir um relativo acordo quanto ao fato de que grande parte da legislação brasileira vigente é desatualizada, tendo sido elaborada para uma sociedade que pouco se parece com a atual, obrigando juízes a aplicar normas em muitos casos ultrapassadas. A dvoga-se que o país deveria acompanhar uma tendência mundial no sentido de um enxugamento da legislação, de uma redução da intermediação judicial, da livre negociação e da auto-resolução dos conflitos.

$\mathrm{N}$ a esfera legislativa tornou-se imprescindível ajustar a lei aos imperativos da justiça, sem que isto implique diminuir o respeito ao devido processo legal e ao direito de defesa. A lei processual brasileira permite, de fato, uma pletora de recursos. Pode-se, como lembram seus críticos, até fazer embargo de declaração de despacho a embargo de declaração. Esta estratégia tem claramente como objetivo ganhar tempo, retardando a sentença final.

Ainda em relação à legislação processual, há propostas que buscam limitar as possibilidades de medida liminar ou cautelar. M uitos juristas julgam que todas as situações jurídicas hoje são passíveis de serem postas em suspenso por medida liminar ou cautelar, sendo até mesmo executadas em favor do autor antes que 0 réu tenha sido ouvido. 
H á também forte demanda de desburocratização das exigências legais. Considera-se que a simplificação dos procedimentos pode significar economia de tempo e de custos, sem colocar em risco garantias próprias do devido processo legal e direitos individuais.

Q uanto aos mecanismos alternativos de solução de disputas, medidas já vêm sendo implementadas no sentido de institucionalizar a conciliação, a negociação e a arbitragem. 0 juízo arbitral, a chamada "Lei Maciel", já foi, inclusive, regulamentado. M as o país ainda está muito distante de aproveitar todo o potencial das soluções alternativas para a solução de disputas (ADR).

Essas propostas, classificadas em judiciais e extrajudiciais, não esgotam 0 amplo leque de alterações que tem por meta modificar o Poder J udiciário e o sistema de justiça em geral. H á outraspropostas, como por exemplo: alteração dos dispositivos relativos à promoção dos magistrados; introdução de participação do M inistério Público no concurso de provas e títulos para ingresso na carreira da magistratura; modificação de dispositivo referente ao vitaliciamento do magistrado; estabelecimento de investidura temporária para os M inistros dos ST F e do ST j; proibição de realização de sessões secretas, pelos tribunais, para tratar de assuntos administrativos; extensão para os M inistérios Públicos dos Estados e do $D$ istrito F ederal do mecanismo de confirmação pelo Poder L egislativo da escolha do Procurador-G eral, hoje existente para o M inistério Público Federal; quarentena para juiz que se aposenta; quarentena para nomeação para qualquer tribunal de quem tenha exercido mandato eletivo ou ocupado cargo de ministro de Estado.

Ao lado de temas que exigem mudanças constitucionais ou na legislação ordinária, há aqueles que modificariam o J udiciário no sentido de transformá-lo em uma máquina mais moderna e menos avessa às inovações tecnológicas. Esse problema, tal como os demais, não é novo, mas acentuou-se nos últimos anos. Atualmente, 0 anacronismo da máquina judicial atinge muito mais a primeira instância do que os tribunais, ainda que também nesses ainda não se tenha aproveitado por inteiro as vantagens da informatização.

Parece inquestionável que a atual estrutura do Judiciário não tem sido capaz de atender minimamente às exigências de um serviço público voltado para a cidadania. 0 atual modelo, contudo, não provoca malefícios de forma homogênea. $\mathrm{H}$ á indícios de que a morosidade e a possibilidade de um grande número de recursos, retardando uma decisão final, têm favorecido os principais usuários do J udiciário. É forçoso reconhecer, entretanto, que a pauta de reformas é ampla e que dificilmente se obterá consenso. O s apoios são precários, com composições que se modificam de acordo com o item em discussão.

\section{M udanças e perspectivas de reforma}

À primeira vista, não haveria como se contrapor ao argumento segundo o qual o Judiciário deve ser retratado como uma instituição muito refratária às marcas do tempo. Essa imagem, contudo, vem sofrendo abalos, por vezes 
imperceptíveis, outras visíveis, mas sempre com capacidade de colocar em xeque traços velhos, que se queria antigos.

D o ponto de vista da quebra de velhos traços, duas experiências devem ser sublinhadas: os] uizados E speciais e as iniciativas de al guns magistrados de colocar em prática sistemas de gerenciamento e agilização de varas, cartórios e tribunais, bem como de dar prioridade a formas alternativas de solução de disputas.

O s J uizados E speciais representam a mais importante mudança vivida pelo J udiciário, tanto no que se refere à ampliação do acesso à justiça estatal como na própria concepção de justiça. Efetivamente, criados ainda sob o regime militar, em 1984, no M inistério da D esburocratização, como J uizadosdeP equenasC ausas, tinham por finalidade abrir as portas do Judiciário para novas demandas - de reduzido valor econômico - e propiciar respostas eficientes, orientadas pelos princípios da conciliação, da oralidade, da simplicidade dos procedimentos, da celeridade e amplitude dos poderes do juiz. A Constituição de 1988 reconheceu os êxitos da experiência e consagrou esses J uizados em dois dispositivos (arts. 24, n. X, e 98, n. I).

Em 1995, foi promulgada a L ei 9.099 dispondo sobre os J uizados Especiais Cíveis e C riminais. A alteração mais significativa na parte civil consistiu na ampliação de sua competência. Passou a chamar de "causas de menor complexidade" 0 que a lei anterior denominava de "pequenas causas". A ampliação da competência para causas até quarenta salários mínimos; possibilidade de execução, sem processo de conhecimento, de título executivo extrajudicial; acesso de micro-empresas pode significar um desvirtuamento das finalidades expressas na criação desses juizados, sobretudo a de facilitar o acesso à J ustiça do cidadão comum e principalmente dos mais humildes.

Sublinhe-se que o objetivo central desses juizados não é resolver a crise do J udiciário, mas democratizar o acesso, propiciar um espaço para o desenvolvimento de uma nova mentalidade e para o tratamento processual mais adequado de causas de menor complexidade, tornando a instituição um serviço público capaz de chegar a soluções de controvérsias (julgamento e execução), de forma barata e rápida.

Para a consecução dessa finalidade maior, o legislador criou um microsistema processual, privilegiando: o acesso direto e gratuito do interessado; a informalidade; a simplicidade e a celeridade processuais; a valorização da conciliação e da solução amigável, com a criação da figura de conciliador; instituiu um sistema recursal diferenciado, formado por juízes de primerio grau de jurisdição; previu as figuras de árbitro e de juiz leigo. Além disso, cumpre ao sistema informar e orientar os usuários e garantir a efetiva participação da comunidade na administração da J ustiça.

A participação da comunidade, a adoção de meios alternativos de solução de conflitos (principalmente a conciliação e o arbitramento) e ainda as tendências 
a maior informalidade e a menor legalismo constituem a grande inovação desses juizados. Trata-se, fundamentalmente, de uma experiência que depende e gera uma nova mentalidade nos operadores do D ireito, mais aberta e menos formalista, principalmente nos juízes, serventuários da justiça, advogados, procuradores e promotores, substituindo a postura de árbitro, em um jogo de soma zero, por uma de pacificação, em uma arena de composições e acertos.

$\mathrm{N}$ a experiência concreta, há E stados que conseguiram avançar mais e outros muito pouco na organização dos juizados e na consecução de suas finalidades. A rigor, isto indica que ainda é baixo o seu grau de institucionalização, estando sujeitos à oscilação da vontade política dos dirigentes do Judiciário local .

A despeito das deficiências, os juizados têm permitido: 0 ingresso de novas demandas; a ampliação do acesso da população; a constituição e o desenvolvimento de novas formas de justiça, gerando características novas, capazes de conviver com as antigas, mas colocando em xeque valores obsoletos.

Tal como os J uizados E speciais, experiências de colocar em prática princípios de gerenciamento e racionalização de procedimentos, e de valorizar a conciliação têm mostrado resultados concretos: aumentos de produtividade e, mais significativo, concretização no juízo comum de uma nova mentalidade - menos formalista, menos burocrática e mais atenta às demandas da cidadania.

Essas práticas, com alto potencial de questionar obsolescências e imprimir uma nova identidade ao J udiciário, não dependem de mudanças constitucionais, mas de vontade política ou de abertura da instituição para conquistas da modernidade.

Q uanto às alterações na Constituição, apesar da crescente insatisfação com o J udiciário, projetos de reforma não conseguiram adquirir o statusde prioridade. Em uma agenda repleta de demandas por mudanças, outros foram os alvos principais. A reforma do Judiciário e das instituições do sistema de justiça permanece na pauta do Congresso N acional desde 1992 e nada indica que a votação do projeto como um todo será concluída num futuro próximo.

O governo Luiz Inácio Lula da Silva, contudo, tem dado sinais de que mudanças no Judiciário devem ser implementadas, mesmo que isto implique confrontos com a instituição e o "fatiamento" da proposta de emenda constitucional. D e fato, iniciativas governamentais deram mais concretude à reforma. $D$ entre elas, a mais importante foi à criação, em maio de 2003, da secretaria de R eforma do J udiciário, no âmbito do M inistério daJ ustiça. Essa secretaria tem coordenado discussões sobre o tema e apresentado sugestões que prescindem de mudanças constitucionais, como por exemplo, melhorias na gestão com a modernização e a informatização de varas, fóruns e tribunais.

Por outro lado, após o governo Lula da Silva, recrudesceram acentuadamente as críticas ao J udiciário. 0 próprio presidente proferiu avaliações negativas. As críticas foram constantes durante todo o primeiro ano de mandato, a ponto 
de se criar uma situação que alguns chegaram a qualificar como de crise institucional. Tais críticas não foram exclusividade do Executivo. Também no L egislativo vários pronunciamentos tiveram por tema as deficiências do J udiciário. Além disso, em outubro de 2003, houve uma proposta de uma representante da O NU de se fazer uma espécie de auditoria no J udiciário, em função da impunidade criminal. Também a secretária-geral da Anistia I nternacional, ao entregar o relatório da entidade, cobrou do presidente Lula a reforma do Judiciário, especialmente na área criminal, além da adoção de políticas que assegurem o acesso dos mais pobres à J ustiça.

Integrantes do Judiciário, como não poderia deixar de ser, reagiram às críticas, particularmente as oriundas do Poder Executivo. As respostas mais ásperas vieram do então presidente do STF, M aurício Correa, e do presidente da Associação dos M agistrados do Brasil, Claudio Baldino M aciel.

Do ponto de vista do jogo político, na disputa Executivo e Judiciário, a balança tem pendido claramente a favor do governo, que reúne inúmeras vantagens. Para começar, são praticamente unânimes as críticas ao Judiciário. Ademais, por ocasião da discussão da R eforma Previdenciária, o J udiciário ficou com a imagem ainda mais desgastada, uma vez que suas posições foram vistas como essencialmente corporativas e de defesa de privilégios. A magistratura chegou, inclusive, a ameaçar o governo com uma greve, que acabou sendo cancelada. Tal reação - com traços de comportamento fortemente sindicalista - acentuou a imagem negativa do Judiciário junto à opinião pública.

D a ótica do governo, a reforma do Judiciário daria vigor a uma agenda positiva. $\mathrm{N}$ a presente conjuntura, os interesses da magistratura podem ser mais facilmente neutralizados e identificados como particularistas, sectários e contrários aos princípios da igualdade e dos interesses sociais. A gestão de M aurício Corrêa na presidência do ST F acabou por fornecer mais argumentos para os partidários da reforma. D urante seu mandato, o ministro revelou exacerbado corporativismo, ânimo para disputas e provocou, com suas manifestações e reações, excessiva presença nos noticiários. A defesa dos interesses da magistratura, ainda que legítima, transpareceu como reivindicação corporativa em pró, não de direitos, mas de regalias e privilégios.

Some-se, ainda, aos fatores favoráveis à reforma, o impacto provocado pelo último escândalo envolvendo juízes, conhecido como "operação Anaconda" e a ocorrência de uma onda reformista do sistema de justiça atingindo vários países da América L atina ${ }^{16}$. Ademais, buscam-se aliados junto à própria magistratura, tendo por base a percepção de que há um grupo de descontentes com a situação atual e, também, que é possível valorizar e multiplicar experiências inovadoras.

Para o governo ou, mais especificamente, para a Secretaria de R eforma do J udiciário, a reforma deveria ser fatiada. I sto é, deveriam ser discutidos e votados primeiramente os pontos sobre os quais há acordo, ou pelo menos possibilidades de se atingir uma ampla maioria de votos. Além disso, essa estratégia distingue 
mudanças que necessitam de reforma constitucional de mudanças infra-constitucionais.

$\mathrm{N}$ o que se refere à mudança constitucional, al guns temas são considerados prioritários para o governo: a criação de um órgão de controle externo; a federalização dos crimes contra os direitos humanos; a quarentena de ingresso e de saída dos magistrados; a súmula impeditiva de recursos; uniformização dos critérios de ingresso na magistratura e no M inistério Público; autonomia das defensorias públicas.

Esses temas estão longe do consenso. Assim, por exemplo, se é considerável o apoio à criação de um conselho para exercer a fiscalização do Judiciário, são apreciáveis as divergências quanto à composição desse órgão. Segundo o relatório da deputada Zulaiê Cobra Ribeiro, aprovado na Câmara dos D eputados e em discussão no Senado, o conselho seria composto por quinze membros: nove juízes, dois representantes da $O A B$, dois membros do M inistério Público e dois cidadãos, um indicado pela Câmara e outro pelo Senado. O governo e o PT prefeririam um conselho em que os juízes fossem minoria, mas, face às resistências, sobretudo por parte da magistratura, têm apoiado a proposta que tramita no Congresso, insistindo na necessidade de sua aprovação imediata, com poder, inclusive, para demitir juízes corruptos.

O s magistrados, por seu lado, estão divididos. Pondere-se, contudo, que já é possível registrar mudanças e, mais do que isto, o placar contrário ao controle externo verificado no ST F alterou-se a partir de maio de 2004, com a aposentadoria compulsória de M aurício Correa, que sempre se manifestou radicalmente contrário a esse mecanismo. Seu substituto, como os três últimos já nomeados, foi indicado pelo presidente Lula da Silva. Além disso, o novo presidente do ST F, N . J obim, é o principal aliado do governo para a criação de um órgão de controle externo. A mesma tendência verifica-se no ST J. Face, pois, às alterações na correlação de forças, parece cada vez mais difícil descartar algumas alterações constitucionais, entre elas, a criação de um órgão de controle externo do J udiciário.

Fortalece-se, assim, a hipótese segundo a qual os ventos de mudança têm atingido e continuarão a atingir o Judiciário. Poucas vezes o debate esteve tão acalorado, tantos buscaram negociar e assim alterar suas posições iniciais, e projetos, ou pelo menos itens de projetos, ganharam tanta concretude, permitindo concluir que dificilmente uma instituição tão cristalizada como o Judiciário permanecerá imune a alterações. As mudanças em curso e o rompimento com 0 marasmo são passos surpreendentes para os céticos; pequenos para os ideal istas; necessários, bem-vindos, mas insuficientes para garantir uma justiça mais célere, imparcial e de amplo acesso para os realistas, orientados pelos princípios republicanos. É preciso mais - é o clamor da cidadania. 


\section{N otas}

10 paradigma desse novo modelo de Constituição é a Lei Fundamental de Bonn, de 1949. A Constituição portuguesa de 1976 e a espanhola de 1978 são recorrentemente apontadas como exemplos que se enquadram nesse padrão.

2 M esmo que se saliente que as Constituições da segunda metade do século XX são muito mais extensas do que suas antecessoras, a Constituição argentina possui apenas 129 artigos e dezessete dispositivos transitórios e resultou de uma discussão entre juristas de cada partido antes de ser levada ao Parlamento

3 Para a discussão do modelo de controle da constitucionalidade adotado e suas conseqüências para a vida pública e para a governabilidade, ver Arantes, 1997.

4 A pós a C onstituição de 1988 passaram a ser nove os possíveis titulares de ação direta de inconstitucionalidade: o presidente da República; a M esa do Senado Federal; a M esa da C âmara dos D eputados; a M esa da Assembléia L egislativa; o Governador de Estado; o Procurador-Geral da República; o Conselho Federal da Ordem dos Advogados do Brasil; partido político com representação no Congresso N acional; confederação sindical ou entidade de classe de âmbito nacional.

50 I desp realizou uma série de pesquisas junto aos operadores do direito. Todas elas tiveram o apoio da Fundação Ford e da Fapesp. O s dados relativos à opinião da magistratura, colhidos em 1993, encontram-se em Sadek (1995b). A opinião dos integrantes dos M inistérios Pœblicos dos Estados (pesquisa feita em 1996) está em Sadek (1997). O s resultados da pesquisa realizada em 1997 junto aos integrantes do M inistério Público Federal encontram-se em Sadek e Castilho (1998).

6 Efetivamente, dados do IBGE de 1988 mostram que a maior parte dos litígios sequer chega a uma Corte de J ustiça - apenas $33 \%$ das pessoas envolvidas em algum tipo de litígio procuram solução no Judiciário.

7 Cappelletti e Garth (1988, p. 12), em texto que se tornou referência obrigatória para os estudiosos do sistema de justiça, afirmam que "a titularidade de direitos é destituída de sentido na ausência de mecanismos para sua efetiva reivindicação. 0 acesso à justiça pode ser encarado como o requisito fundamental - o mais básico dos direitos humanos - de um sistema jurídico moderno e igualitário que pretenda garantir, e não apenas proclamar os direitos de todos".

8 Carvalho (1997, p. 105) baseado em dados de pesquisa conclui que o sistema de justiça "é inacessível à grande maioria dos brasileiros. Para eles, existe o Código Penal, não o Código Civil".

9 Solicitados a avaliar os resultados econômicos das ações propostas por suas empresas nosúltimos dez anos, 59\% responderam que os benefícios superaram os custos; $11 \%$ que os custos superaram os benefícios; $13 \%$ que os custos e benefícios foram aproximadamente iguais; 17\% não souberam avaliar (I desp, 1996).

$10 \mathrm{D}$ ados oficiais de 2004 indicam que o Brasil possui um juiz para cada 25 mil habitantes, havendo vacância na justiça dos Estados, na federal e na trabalhista. $O$ déficit chega a $21 \%$ na justiça comum. 
11 Dados da pesquisa I desp (Sadek, 1995b) realizada junto à magistratura mostram que $55 \%$ dos juízes ingressaram no Judiciário com trinta anos ou menos. Segundo resultados da pesquisa de Vianna et al. (1997) observa-se uma tendência de recrutamento de integrantes cada vez mais jovens: enquanto em 1985/ 1986 os ingressantes com trinta anos ou menos correspondiam a 29,3\%do total, nos concursos entre 1993/ 1994 eles passaram para 48\%.

$12 \mathrm{~A}$ pluralidade de opiniões pode ser confirmada nos resultados de pesquisa realizada pelo I desp em 2000, junto a 738 juízes, de primeira e segunda instâncias, em onze Estados da federação. A análise das opiniões sobre a reforma do Judiciário está em Sadek, Arantes e Pinheiro, 2001.

13 Pesquisas do I desp mostraram que tem crescido o grupo de magistrados que julga que 0 juiz não pode ser um mero aplicador da lei, deve ser sensível aos problemas sociais. Para a comparação ver Sadek, 1995a e Sadek, Arantes e Pinheiro, 2001.

140 processo de revisão da Constituiçãa, previsto pelo Ato das Disposições Constitucionais Transitórias, teve inicio em 13/ 10/ 1993 e encerrou em 31/ 5/ 1994. $\mathrm{N}$ esta fase especial, o Congresso $\mathrm{N}$ acional, reunido em sessão unicameral, poderia aprovar mudanças na Constituição pelo voto da maioria absoluta de seus membros. U m processo normal de emendas à Constituição deve respeitar a regra de votação em dois turnos, nas duas casas legislativas, por meio de maioria qualificada de 3/ 5, nas quatro votações.

15 Jairo Carneiro do PFL da Bahia foi escolhido relator em 1995. Sucederam-Ihe dois deputados federais do PSD B de São Paulo: Aloysio N unes Ferreira e Zulaiê Cobra Ribeiro.

$16 \mathrm{~N}$ a Argentina, o presidente Kirchner promoveu mudanças no Judiciário assim que assumiu o cargo. Dois magistrados renunciaram ao cargo de ministro da Corte Suprema de J ustiça, devido a acusações. No início de dezembro de 2003, o Senado destituiu um ministro da Corte Suprema de J ustiça. M oliné $\mathrm{O}$ 'C onnor foi considerado culpado das nove acusações que pesavam contra ele. 0 juiz criou a "maioria automática", pela qual cinco dos nove magistrados sempre votavam a favor do Executivo durante o governo C. M enem (1989-1999). N o Paraguai, o presidente D uarte Frutos liderou um processo de "limpeza". Como resultado, em quatro meses, de agosto quando assumiu o poder - até o final de novembro de 2003, dos nove ministros da Corte Suprema, três renunciaram e três foram submetidos a um julgamento político na Câmara dos D eputados e no Senado.

\section{Bibliografia}

ARANTES, Rogério Bastos. J udiciário ePolítica no Brasil. São Paulo, Sumaré/ Fapesp/ Educ, 1997.

CAPPELLETTI, M auro e BRYANT, Garth (eds.).A ccessto J ustice Milan/ Alphenaandenrij, D ott Giuffrè/ Sijthoff and N oordhoff, 1978.

CARVALH O, J osé M urilo. "Cidadania: tipos e percursos", em EstudosH istóricos, Rio de Janeiro, vol. 9, n. 18, 1996. 
IDESP - R elatório de Pesquisa “Justiça e Economia” , São Paulo, 2000.

PINHEIRO, Armando Castelar (org.). R eforma do Judiciário - Problemas, desafios, perspectivas. Book Link, 2003.

SADEK, M aria Tereza (org.). O J udiciário em debate. São Paulo. I desp/ Sumaré, 1995 a).

- - - - (org. ). U ma introdução ao estudo da J ustiça. São Paulo, Sumaré/ Ford, 1995b.

- - - . O M inistério Público ea justiça no Brasil. São Paulo, I desp/ Sumaré, 1997.

SAD EK, M aria Tereza e CASTILHO , Ela Wiecko de. O M ini stério Público Federal ea administração da J ustiça no Brasil. São Paulo, Sumaré, 1998.

SADEK, M. T., ARANTES, R. B. ePIN HEIRO, A. C. Osjuízesea reforma doJ udiciário, São Paulo, Tribunal de Alçada C riminal, 2001.

VIAN N A, L uis Werneck et al. Corpo ealma da magistratura brasileira. Rio de Janeiro, Revan/ IU PERJ, 1997.

VIEIRA, O scar Vilhena. "I mpério da L ei ou da Corte". R evista U SP, D ossi êj udiciário, n. 21, 1994.

RESUMO - o JUDICIÁRIO brasileiro, diferentemente do que ocorria no passado, está na berlinda e não apresenta mais condições de impedir mudanças. R eformas virão e mudanças já estão em curso, algumas mais e outras menos visíveis, alterando a identidade e o perfil de uma instituição que sempre teve na tradição uma garantia segura contra as inovações.

A BSTRACT - THE JUDICIAL Branch of the Brazilian government, unlike in the past, is now in a not-so-flattering spotlight and no longer able to prevent changes. Reforms will come and changes are already happening, some more and some less visible, altering the identity and the profile of an institution that had always counted on tradition as an assured guarantee against innovation.

M aria Tereza Sadek é doutora em C iência Política pela U niversidade de São Paulo (U SP), pesquisadora sênior do Instituto de Estudos E conômicos, Sociais e Políticos (I desp) e orientadora científica do C entro Brasileiro de Estudos e Pesquisas J udiciais (C ebepej). É professora da pós-graduação do D epartamento de Ciência Política da U SP e autora de várias obras, entre elas: Maquiavel, Maquiavés a tragédia octaviana (1978), Pensamento Político Clássico (com Célia G. Quirino, 1980), O Judiciário em debate (org., 1995) e Maquiavel: a política como da é (1996).

Texto recebido e aceito para publicação em 15 de junho de 2004. 